
UMDC Faisalabad.

2. Senior Registrar of Surgery, UMDC Faisalabad.

3. Professor of Surgery UMDC Faisalabad.

Correspondence Address: Dr. Irshad Ahmad Assistant Professor of Surgery, UMDC Faisalabad. zahid60@live.com
1. Assistant Professor of Surgery,

\section{SURGICAL MANAGEMENT OF MULTINODULAR GOITRE;}

\section{TOTAL THYROIDECTOMY IS BETTER PROCEDURE THAN SUBTOTAL THYROIDECTOMY FOR THE MANAGEMENT OF MULTINODULAR GOITRE}

\author{
Dr. Irshad Ahmad', Dr. Sarwat ${ }^{2}$, Dr. A. G Rehan
}

\begin{abstract}
Background: A prospective, analytical study conducted to compare the results of total thyroidectomy with subtotal thyroidectomy in the management of multinodular goitre. Objective: comparison of total thyroidectomy and subtotal thyroidectomy for the management of multinodular goitre in terms of postoperative complications. Patients and Methods: A prospective review of 120 patients with benign multinodular goitre (bilateral) undergoing total thyroidecotmy (Group $A=60$ ) and subtotal thyroidecotmy (Group $B=60$ ) during 2 years period (2011-12) was undertaken. Evaluation of results was done by analyzing the data in SPSS version 17. Results: In group A, total thyoidectomy was done, the postoperative complications were lesser (13.33\%) than group B in whom subtotal thyroidectomy was done (16.67\%). The complications seen in group A were seroma formation 1(1.67\%), external laryngeal nerve (ELN) palsy 2 (3.34\%), recurrent laryngeal nerve (RLN) palsy (temporary) $2(3.34 \%)$ and hypoparathyroidism $3(5.00 \%)$. The complications seen in group B were tension haematoma 01 $(1.67 \%)$, seroma formation $2(3.34 \%)$, ELN palsy $2(3.34 \%)$, RLN palsy (temporary) $3(5.00 \%)$ and hypoparathyroidism 2 (3.34\%). No mortality was seen in both groups. Conclusions: Total thyroidectomy is better procedure than subtotal thyroidectomy for the treatment of benign mulitnodular goitre. This procedure also prevents future need of surgery for recurrence and incidental thyroid cancer.
\end{abstract}

Key words: $\quad$ Multinodular Goitre, Total Thyroidectomy, Subtotal Thyroidectomy, post operative complications.

Article received on:

28/02/2014

Accepted for Publication:

$14 / 03 / 2014$

Received after proof reading:

$31 / 05 / 2014$

\section{INTRODUCTION}

Multinodular goitre (MNG) is a common benign endocrine problem with an incidence of $5-12 \%$ in females and $2-5 \%$ in males. Surgery is the mainstay of treatment for multinodular goitre and the recommended procedures are total, near total and subtotal thyroidectomy ${ }^{1,2,17}$. The goal of surgical treatment in benign multinodular goitre should be to eliminate the disease with a low complication rate \& to minimize the necessity for re-operation because the risk of permanent complications have been found to be higher in reoperations for recurrent disease than in primary operations ${ }^{2}$.

Statistics reveal that the total thyroidectomy is increasingly replacing partial thyroid resections. This paradigm shift is substantiated by the comprehension of multinodular goitre as a disease affecting the whole organ as well as the fact that total thyroidectomy avoids high risk secondary interventions for incidental thyroid carcinomas and recurrent disease while offering comparable operative risks ${ }^{3}$.

There is increasing trend towards performing more radical resections instead of a subtotal resection for benign thyroid diseases. Total or near total thyroidectomy procedures are now being increasingly employed to treat bilateral benign thyroid disease and are as safe as the subtotal thyroidectomy procedures which are more 
conservative and associated with significantly higher recurrence rates ${ }^{4}$.

Total thyroidectomy is effective and safe for the surgical treatment of bilateral multinodular goitre to prevent recurrence and to eliminate the need for completion thyroidectomy in case of final diagnosis of incidental thyroid malignancy ${ }^{2,14,16}$.

The objective of our study is to compare total thyroidectomy with the subtotal thyroidectomy in terms of post operative complications.

\section{PATIENTS \& METHODS}

This prospective study was done in surgical ward of Madina Teaching Hospital, Faisalabad from January 2011 to December 2012. In this two years period, 120 patients included in this study who were divided into two groups, 60 patients in Group A underwent total thyroidectomy $\& 60$ patients in group B underwent subtotal thyroidectomy. Inclusion criteria comprised of patients of benign multinodular goitre which were operated for relieving different pressure symptoms \& for cosmetic reasons. Exclusion criteria included patients with known or suspicion of thyroid cancer, Graves disease, recurrent goitre, solitary thyroid nodule and previously operated cases by unilateral lobectomy. Preoperative investigations included routine tests for fitness of patient, thyroid function tests. Thyroid scan, USG neck \& FNAC were performed selectively. Antithyroid drugs were given where indicated. Preoperative calcium level \& indirect laryngoscopy (IDL) were done in all patients.

All cases were performed by consultant surgeons working in Madinah Teaching Hospital. All operations were done under general anaesthesia with neck hyperextended \& head slightly raised $\left(15^{\circ}\right)$ using Kocher's thyroid incision i.e. incision two finger breadth above sternal notch from one sternomastoid to the other. In a few cases(huge goitre) incision was extended in posterior triangle. Flaps were raised-upper flap up to thyroid cartilage \& lower flap upto sterno clavicular joint. All other steps mentioned in literature for conventional thyroidectomy were followed. In group A, 60 patients in whom total thyroidectomy was done, both lobes, isthmus and pyramidal lobe removed entirely. The main trunk of inferior thyroid artery was not ligated rather individual branches of inferior thyroid artery were ligated to save blood supply to parathyroid glands. In group B, 60 patients in whom subtotal thyroidectomy was done, 8-10grams thyroid tissue retained on both sides. Haemostasis secured meticulously in both groups. Drain placed \& wound closed. Postoperative serum calcium level was done after 24 hours \& 48 hours post operatively. The complications were recorded on data sheets and were analysed by using SPSS-V-17. Post operatively patients were evaluated for complications in follow up period of one year.

\section{RESULTS}

Total one hundred and twenty (120) patients with MNG were included in this study who were divided into 2 groups. In group A (60 patients), total thyroidectomy was done, 55(91.66\%) were females \& 5(8.34\%) were males. Post operative complications are less (13.33\% vs $16.67 \%$ ) Eight patients (13.33\%) were experienced to have postoperative complications, 2 patients (3.34\%) had hoarseness of voice (RLN palsy). It was transient and recovered within two weeks. Two patients (3.34\%) had low pitch of voice (ELN palsy). It was also transient and recovered conservatively. Three patients (5.00\%) presented with features of hypocalcemia. They were treated with IV calcium gluconate and recovered. Other complication was wound related i.e seroma formation in 1 patient (1.67\%).

In group B (60 Patients), Subtotal thyroidectomy was done. Fifty two (86.67\%) were females and eight $(13.33 \%)$ were males. Post operative complications were comparatively more. One patient (1.67\%) experienced tension haematoma, who was re-explored immediately and ligation of bleeding vessel was done. Wound complication i.e. seroma formation in 2 (3.34\%), ELN palsy 2 (3.34\%), RLN Palsy 3(5.00\%) and temporary hypoparathyroidism 2 (3.34\%). No mortality was seen in both groups. 


\begin{tabular}{|l|c|c|}
\hline \multicolumn{1}{|c|}{ Complications } & $\begin{array}{c}\text { Group A (NTT) } \\
\mathbf{n = 6 0}\end{array}$ & $\begin{array}{c}\text { Group B (STT) } \\
\mathbf{n = 6 0}\end{array}$ \\
\hline Patients with no complication & $52(86.67 \%)$ & $50(83.33 \%)$ \\
\hline Patients with complications & $8(13.33 \%)$ & $10(16.67 \%)$ \\
\hline Tension Haematoma & - & $01(1.67 \%)$ \\
\hline Wound complication, Seroma Formation & $1(1.67 \%)$ & $2(3.34 \%)$ \\
\hline External Laryngeal N Palsy & $2(3.34 \%)$ & $2(3.34 \%)$ \\
\hline $\begin{array}{l}\text { Recurrent Laryngeal N Palsy } \\
\text { Temporary } \\
\text { Permanent }\end{array}$ & $2(3.34 \%)$ & $3(5.00 \%)$ \\
\hline $\begin{array}{l}\text { Hypoparathyroidism } \\
\text { Temporary } \\
\text { Permanent }\end{array}$ & - & - \\
\hline Mortality & $3(5.00 \%)$ & $2(3.34 \%)$ \\
\hline \multicolumn{1}{|c|}{ Comparison of Total Thyroidectomy (Group A) and Subtotal thyroidectomy (Group B) in terms of postoperative } \\
\hline
\end{tabular}

On histology, incidental thyroid carcinoma (Papillary) was found in 3 patients(2.5\%), one in total thyroidectomy \& 2 in subtotal thyroidectomy. These patients were sent for thyroid ablation.

\section{DISCUSSION}

Although surgery is the recommended treatment for MNG but there is still controversy upon the extent of thyroidectomy ${ }^{5}$. Subtotal thyroidectomy was considered safe because of low complication rate but currently the procedure of choice is total thyroidectomy ${ }^{6}$ because MNG affects the entire gland $^{22}$. If a surgeon leaves abnormal thyroid tissue, subsequent re-operation might be required ${ }^{7}$. Re-operations are also under taken, if there is postoperative histological evidence of incidental thyroid carcinoma in MNG and these are associated with higher complications rate as compared with primary procedure ${ }^{8}$. There are also chances of malignacy in remaining thyroid tissue. The chances of complications are more in reoperations because of difficult dissection due to adhesions. That is why; recently the trend is changing in surgical practice from subtotal to total or near total thyroidectomy ${ }^{9}$. In our study, we have compared the total thyroidectomy with the subtotal thyroidectomy and the postoperative complications were recorded. The comparative results have shown lesser rate of complications in total thyroidectomy than subtotal thyroidecotmy (13.33\% vs $16.67 \%)$. Our study has also shown, if surgery has been performed by expert surgeons using intracapsular dissection ${ }^{10}$ and routinely identifying recurrent laryngeal nerve, the chances of complications are minimized especially permanent complications regarding recurrent laryngeal nerve and parathyroid glands which are more troublesome. In our study, we have not seen a single case of permanent RLN injury or permanent hypoparathyroidism. Most complications were wound related, temporary nerve palsy and transient hypocalcaemia which were managed conservatively. Also we have not seen any case of recurrence in our study, this is because most of the recurrences are developed in 10-20 years after primary surgery ${ }^{11}$ and postoperative follow up period in our study was only one year. The incidence of recurrence after subtotal thyroidectomy varies in different studies and may be as high as $23 \% \%^{9,22,28}$ and it carries the risk for increased surgical morbidity during the course of re-operation ${ }^{15,21,25,27}$. Re-operation for recurrent disease carries a significant risk of damage to both RLNs and parathyroid glands and during completion thyroidectomy, these is 10 fold increase in iatrogenic injuries ${ }^{22}$. This supports total 
thyroidectomy as procedure of choice ${ }^{6,30}$.

Another aspect that favours total thyroidectomy (instead of subtotal thyroidectomy) is finding incidental thyroid malignancy on histopathology report. The incidence of occult malignancy is generally thought to be $7-10 \%^{9,23}$, so in the presence of unrecongnized malignancy, subtotal thyroidectomy represents inadequate surgery ${ }^{29}$. Although only three cases $(2.5 \%)$ of incidental thyoid cancer are found in our study, the figure is many more in other studies e.g. $18 \%^{2}$ and $7.7 \%{ }^{17}$. Obviously total thyroidectomy prevents from redo surgery (Completion Thyroidectomy) in these cases.

Moreover malignant transformation in the thyroid remnant after subtotal resection ranges from 4$17 \%{ }^{25}$, this again supports total thyroidectomy as better surgical option. One potential reason for performing subtotal thyroidectomy is maintenance of euthyroid status without thyroxine replacement. It is well documented that leaving a small thyroid remnant in situ will not prevent the onset of hypothyroidism ${ }^{9,24,26}$ and all patients required a minimum of $100 \mathrm{~g}$ thyroxine daily. So thyroxine replacement is essential for the whole life wheather you perform total thyroidecotmy or subtotal thyroidectomy ${ }^{17,18,19}$.

The main reason for performing subtotal thyroidecotmy is a presumed lower incidence of postoperative complications, including RLN palsy and hypoparathyroidism. Our study has shown that in experienced hands the postoperative complications are less in total thyroidectomy as compared with subtotal thyroidectomy. For example, recurrent laryngeal nerve palsy occurred in 2 patients(3.34\%) in total thyroidectomy and 3 patients $(5 \%)$ in subtotal thyroidectomy which is comparative to study in which transient vocal cord paralysis occurred in 11 $(3.2 \%)$ cases and in $1(0.3 \%)$ case, it became permanent $^{5}$. There was significant increase in incidence of recurrent laryngeal nerve injury in secondary operations $(21.7 \%$ in secondary vs $2.8 \%$ in primary $)^{12}$. In another study, the temporary recurrent laryngeal nerve palsy rate was 3.3\% whereas temporary hypoparathyroidism was $7.2 \%$ in total thyroidectomy ${ }^{13}$. In our study, temporary hypoparathyroidism occurred in $5 \%$ of cases in total thyroidectomy and $3.34 \%$ in subtotal thyroidectomy, there was no case of permanent hypoparathyroidism. So total thyroidectomy is safe and preferred option even for benign multinodular goiter and is associated with minimal complications $\mathbf{s}^{5,15}$.

\section{CONCLUSIONS}

Total thyroidectomy is better procedure than subtotal thyroidectomy for the management of benign multinodular goitre due to lesser number of complications. This procedure also prevents future need of surgery for recurrence and incidental thyroid cancer.

Copyright(C) 14 Mar, 2014.

\section{REFERENCE}

1. Harrison B.J., Maddox P.R, Smitth DM; Disorders of the thyroid gland. In cuschieri A, Steele RJ, Moosa AR, editors. Essential Surgical Practice Vol. 2, 4th ed London; Arnold 2002: 95-110.

2. Guraya SY, Al-Zobydi AH; Total and Near-total Thyroidectomy is better than Subtotal Thyroidecomy for the treatment of bilateral Benign Multinodular Goitre; A Prospective Analysis Br. J Med 1 (1):1-6, 2011.

3. Musholt TJ.Chirurg. Total thyroidectomy for multinodular goiter. $2010 \mathrm{Jul} ; 81$ (7):603-6.

4. Citqez B, Uludaq M, Yetkin C, Yuer E, Akgum I, Isqn A. Changes in choice of thyroidectomy for benign thyroid disease. Surg Today.2013 Jun;43(6):62531.

5. Lateef A, Sajid M, Yaqoob M, Bibi S, Misbah J; total thyroidectomy as preferred option for benign disease - our experience of 152 cases. JUMDC Vol.3, Issue 1, 2012,16-21.

6. Agarwal G and Agarwal V. Is total thyroidectomy the procedure of choice for benign multinodular goiter? An evidence based review. World J Surgery 2008; 32(7): 1313-24.

7. Thomusch O; Machen's A, Sekulla C; et al. Multivariate analysis of risk factors for postoperative complications in benign goiter surgery; prospective multicenter study in Germany. World J. Surg 2000; 24, 1335-1341. 
8. Siragusa, G., Lanzara, P., Di Pace, G. Subtotal thyroidectomy or total thyroidectomy in the treatment of benign thyroid disease: our experience. Minerva Chir, 1998; 53, 233-238.

9. Delbridge, L., Guinea, A.I., Reeve, T.S. Total thryoidectomy for bilateral benign multinodular goiter: effect of changing practice. Arch. Surg 1999; 134, 1389-1393.

10. Fouad Abdelshaheed. Total thyroidectomy for clinically benign thyroid disease: A preferred option with capsular dissection technique. E J July 2006; Vol. 25 No. 3.

11. Candela G; Variale S; Di Libero L et al. Nearly Total Thyroidectomy versus total thyroidectomy: Our experience Minerva Chir, 2006; 61, 17-24.

12. Zakaria HM, Al Awad NA, Al Kreedes AS, Al Mulhim AM, Al Sharway MA, et al. Recurrent laryngeal nerve injury in thyroid Surgery. Oman Med J,2011 Jan;26(1):34-8.

13. Acun Z, Comert M, Cihan A, Ulukent Sc, Veen B, et al. Near total thyroidectomy could be the best treatment for thyroid diseases in endemic regions. Arch Surg.2004 Aprl,139(4):444-7.

14. Guraya SY and Eltinay OA. Total Thyroidectomy for Bilateral Benign Thyroid Disease: Safety Profile and Therapeutic Efficacy. Kuwait Medical Journal. 2007; 39 (2): 149-152.

15. Reeve, T.S., Delbridge, L., Coheri, A., Crummer, P. Total thyroidectomy; the preferred option for multinodular goiter. Ann. Surg., 1987;206, 782786.

16. Efremidou El, Papageorgiu MS, Liratzopolus $\mathrm{N}$ et al. The efficacy and safety of total thyroidectomy in the management of benign thyroid disease: $A$ review of 932 cases. Can J Surg. 2009 Februray; $52(1): 39-44$.

17. Ozbas, S., Kocak, S., Aydintug, S. et al. Comparison of the complications of subtotal, near total and total thyroidectomy in the surgical management of multinodular goitre. Endocrine J., 2005; 52, 199205.

18. Colak, T., Akca, T., Kanik, A., Yapici, D., Aydin, S. Total versus subtotal thyroidectomy for the management of benign multinodular goiter in an endemic region. Aust. N. Z. J. Surg., 2004; 74, 974978.
19. Vaiman, M., Nagibin, A., Hagag, P., Buyankin, A., Olevson, J., Shlamkovich, N. Subtotal and near total versus total thyroidectomy for the management of multinodular goiter. World $\mathrm{J}$. Surg., 2008; 32, 1546-1551.

20. Koh KBH, Chang KW. Carcinoma in multinodular goitre. Br J Surg 1992;79: 266-267.

21. Cohen-Kerem R, Schachter P, Sheinfeld M, Baron E, Cohen $O$. Multinodular goiter: The surgical procedure of choice. Otolaryngol Head Neck Surg 2000; 122: 848-850.

22. Reeve TS, Delbridge L, Brady P, Crummer P, Smyth C. Secondary thyroidectomy: a twenty-year experience. World J Surg 1988; 12: 449-453.

23. Wheeler $\mathrm{MH}$. Total thyroidectomy for benign thyroid disease. Lancet 1998; 351:1526-1527.

24. Marchesi M, Biffoni M, Tartaglia F, Biancari F, Campana FP. Total versus subtotal thyroidectomy in the management of multinodular goiter. Int Surg 1998; 83: 202-204.

25. Jacobs J, Aland J, Ballinger J. Total thyroidectomy: a review of 213 patients. Ann Surg 1983; 197: 542549.

26. Harrer P, Broecker M, Zint A, Schatz H, Zumtobel V, Derwahl $M$. Thyroid nodules in recurrent multinodular goiter are predominantly polyclonal. J Endocrinol Invest 1998; 21: 380-385.

27. Rojdmark J, Jarhult J. High long term recurrence rate after subtotal thyroidectomy for nodular goitre. Eur J Surg 1995; 161: 725-727.

28. Piraneo S, Vitri P, Galimberti A, Guzzetti S, Salvaggio A, Bastagli A. Recurrence of goitre after operation in euthyroid patients. Eur J Surg 1994; 160: 351356.

29. Russell CFJ. Management of benign nonendemic goitre. In: Clark OH, Duh QY (eds) Textbook of Endocrine Surgery. WB Saunders, Philadelphia, 1997;22-31.

30. Hisham AN, Azlina AF, Aina EN, Sarojah A. Total thyroidectomy: The procedure of choice for multinodular goitre. Eur J Surg 2001;167: 403-405. 